\title{
JOINT NUMERICAL RADIUS OF SPHERICAL ALUTHGE TRANSFORMS OF TUPLES OF HILBERT SPACE OPERATORS
}

\author{
KAIS FEKI AND TAKEAKI YAMAZAKI
}

Abstract. Let $\mathbf{T}=\left(T_{1}, \ldots, T_{d}\right)$ be a $d$-tuple of operators on a complex Hilbert space $\mathscr{H}$. The spherical Aluthge transform of $\mathbf{T}$ is the $d$-tuple given by $\widehat{\mathbf{T}}:=\left(\sqrt{P} V_{1} \sqrt{P}, \ldots, \sqrt{P} V_{d} \sqrt{P}\right)$ where $P:=\sqrt{T_{1}^{*} T_{1}+\ldots+T_{d}^{*} T_{d}}$ and $\left(V_{1}, \ldots, V_{d}\right)$ is a joint partial isometry such that $T_{k}=V_{k} P$ for all $1 \leqslant k \leqslant d$. In this paper, we prove several inequalities involving the joint numerical radius and the joint operator norm of $\widehat{\mathbf{T}}$. Moreover, a characterization of the joint spectral radius of an operator tuple $\mathbf{T}$ via $n$-th iterated of spherical Aluthge transform is established.

Mathematics subject classification (2010): Primary 47A13; Secondary 47A12, 47A30.

Keywords and phrases: Spherical Aluthge transform, Duggal transform, joint numerical radius, joint spectral radius, joint operator norm.

\section{REFERENCES}

[1] A. Aluthge, On $p$-hyponormal Operators for $0<p<1$, Integral Equations Operator Theory, 13 (1990), 307-315.

[2] T. ANDO, Aluthge transforms and the convex hull of the spectrum of a Hilbert space operator, Recent advances in operator theory and its applications, Oper. Theory Adv. Appl. 160 (2005), 21-39.

[3] R. Bhatia AND C. DAVIS, A Cauchy-Schearz inequality for operators with applications, Linear Algebra Appl. 223/224 (1995), 119-129.

[4] H. BAKLOUTI AND K. FeKI, On joint spectral radius of commuting operators in Hilbert spaces, Linear Algebra Appl. 557 (2018) 455-463.

[5] H. BaKlouti, K. FeKi And O. A. M. Sid Ahmed, Joint numerical ranges of operators in semiHilbertian spaces, Linear Algebra Appl. 555 (2018) 266-284.

[6] C. BenhidA, R. E. CuRTO, S. H. LEE AND J. Yoon, Joint spectra of spherical Aluthge transforms of commuting $n$-tuples of Hilbert space operators, C. R. Math. Acad. Sci. Paris 357 (2019), 799-802, https://doi.org/10.1016/j.crma.2019.10.003.

[7] J. W. BunCE, Models for n-tuples of noncommuting operators, J. Funct. Anal. 57 (1984), 21-30.

[8] G. Corach, H. Porta And L. Recht, An operator inequality, Linear Algebra Appl., 142 (1990), $153-158$.

[9] M. Chō, I. B. Jung AND W. Y. LEE, On Aluthge Transforms of p-hyponormal Operators, Integral Equations Operator Theory, 53 (2005), 321-329.

[10] R. CuRTO AND J. Yoon, Toral and spherical Aluthge transforms of 2-variable weighted shifts, C. R. Acad. Sci. Paris 354 (2016), 1200-1204.

[11] R. CURTO AND J. Yoon, Aluthge transforms of 2 -variable weighted shifts, Integral Equations Operator Theory 90 (2018), Paper number 52, $32 \mathrm{pp}$.

[12] M. Сhō, M. TAKagUCHI, Boundary points of joint numerical ranges, Pacific J. Math 95 (1981), $27-35$.

[13] M. CHŌ, W. ŻELAZKo, On geometric spectral radius of commuting n-tuples of operators, Hokkaido Math. J. 21 (1992), 251-258.

[14] R. E. CURTO, Applications of several complex variables to multiparameter spectral theory. In Surveys of some recent results in operator theory, Vol. II, volume 192 of Pitman Res. Notes Math. Ser., pages 25-90. Longman Sci. Tech., Harlow, 1988.

[15] A. T. DASH, Joint numerical range, Glasnik Mat. 7 (1972), 75-81. 
[16] K. DyKema AND H. SChultz, Brown measure and iterates of the Aluthge transform for some operators arising from measurable actions, Trans. Amer. Math. Soc. 361 (2009), 6583-6593.

[17] C. Folas, I. Jung, E. Ko, C. PeArCy, Complete contractivity of maps associated with the Aluthge and Duggal transforma-tions, Pac. J. Math. 209 (2003) 249-259.

[18] T. FURUTA, Invitation to linear operators. From matrices to bounded linear operators on a Hilbert space, Taylor \& Francis Group, London, 2001.

[19] K. E. Gustafson, The Toeplitz-Hausdorff Theorem of linear Operators, Proc. Amer. Math. Soc. 25 (1970), 203-204.

[20] K. E. Gustafson, D. K. M. Rao, Numerical Range, Springer-Verlag, New York, 1997.

[21] S. Hildebrandt, Numerischer Wertebereich und normale Dilatationen, Acta Sci. Math. (Szeged) 26 (1965), 187-190.

[22] E. HeInZ, Beiträge zur Störungstheoric der Spektralzerlegung, Math. Ann. 123 (1951), 415-438.

[23] I. JUnG, E. Ko AND C. PEARCY, Aluthge transform of operators, Integral Equations Operator Theory 37 (2000), 437-448.

[24] I. B. Jung, E. Ko AND C. PEARCy, Spectral pictures of Aluthge transforms of operators, Integral Equations Operator Theory 40 (2001), 52-60.

[25] J. Kim AND J. Yoon, Aluthge transforms and common invariant subspaces for a commuting $n$-tuple of operators, Integral Equations Operator Theory 87 (2017) 245-262.

[26] J. KIM AND J. Yoon, Taylor spectra and common invariant subspaces through the Duggal and generalized Aluthge transforms for commuting $n$-tuples of operators, J. Operator Theory 81 (2019) 81-105, http://dx.doi.org/10.7900/jot.2017nov27.2210.

[27] S. H. LeE, W. Y. LeE AND J. Yoon, Subnormality of Aluthge transform of weighted shifts, Integral Equations Operator Theory 72 (2012), 241-251.

[28] C. K. LI, C-Numerical Ranges and C-Numerical Radii, Linear and Multilinear Algebra 37 (1994), $51-82$.

[29] C. K. Li And Y. T. Poon, Convexity of the joint numerical range, SIAM J. Matrix Anal. Appl. 21 (1999), 668-678.

[30] V. MÜLLER, AND A. SOLTYSIAK, Spectral radius formula for commuting Hilbert space operators, Studia Math. 103 (1992), 329-333.

[31] G. Popescu, Unitary invariants in multivariable operator theory, Memoirs of the American Mathematical Society, 200 (941), vi+91 pp (2009).

[32] J. G. Stampfli And J. P. Williams, Growth conditions and the numerical range in a Banach algebra, Tôhoku Math. J. 20 (1968) 417-424.

[33] O. Toeplitz, Das algebraische Analogou zu einem satze von fejer, Math. Zeit, 2 (1918), 187-197.

[34] J. L. TAYLOR, A joint spectrum for several commuting operators, J. Funct. Anal. 6 (1970) 172-191.

[35] D. WANG, Heinz and McIntosh inequalities, Aluthge transformation and the spectral radius, Math. Inequal. Appl. 6 (2003), 121-124.

[36] T. YAMAZAKI, On upper and lower bounds for the numerical radius and an equality condition, Studia Math. 178 (2007), 83-89.

[37] T. YAmaZAKI, An expression of spectral radius via Aluthge transformation, Proc. Amer. Math. Soc. 130 (2002), 1131-1137. 